\title{
FANCONI'S ANAEMIA WITH HYDROCEPHALUS AND THYROID ABNORMALITY
}

\author{
BY \\ RUTH LONDON, AHARON DRUKKER, and URI SANDBANK \\ From the Paediatric Department " $A$ " and the Department of Pathology, Kaplan Hospital, Rehovoth, Israel
}

(RECEIVED FOR PUBLICATION JUNE 23, 1964)

Since the first report of three cases of 'familial infantile pernicious-like anaemia' (Fanconi, 1927), more than 100 similar cases have been reported. The condition has been reviewed by Nilsson (1960), Gasser (1961), McDonald and Goldschmidt (1960). Until recently no effective treatment was known, and the pancytopenia was treated by repeated transfusions of fresh blood, and by splenectomy in those cases with evidence of hypersplenism. Shahidi and Diamond (1959) proposed combined corticosteroid and anabolic treatment, and some good results were reported on this regimen (McDonald, 1962; Shahidi and Diamond, 1961). In the following case, which presents some unusual clinical and pathological findings, the pancytopenia was resistant to this therapy.

\section{Case Report}

A 10-month-old girl was referred to our out-patient clinic in August 1961 because of failure to thrive and suspected dwarfism. She was born after a normal confinement which followed an uneventful, slightly prolonged pregnancy, though her birth weight $(2,220 \mathrm{~g}$.), was below normal. The mother received no medication during this, the third of her four pregnancies.

Both parents of Ashkenasi origin were in good health. There was no consangui ity and no known evidence of hereditary or metabolic disease in the parents' families. The first pregnancy resulted in a stillbirth, and the second pregnancy in a third month spontaneous abortion. A younger sister of the patient, at present $1 \frac{1}{2}$ years of age, is in good general health and is developing normally.

Our patient's past history did not disclose anything out of the ordinary, apart from a retardation in physical development. There was no history of contact with a toxic chemical agent or ingestion of a toxic antibacterial drug.

On first examination, at the age of 10 months, she was a small underdeveloped, but fairly well-nourished girl. Her weight was 4,680 g., and her height $59 \mathrm{~cm}$. (both corresponding to the 50th percentiles for the age of 3 months). The head was relatively large, with a circumference of $39 \mathrm{~cm}$. compared with a chest circumference of $34 \mathrm{~cm}$. Otherwise, she was well proportioned. There was marked microphthalmia, but no strabismus, and the greater fontanelle was small, not bulging. In addition, she had severe bilateral dislocation of the hips, bent little fingers, and pointed thin distal phalanges of both thumbs. There was no hepato-splenomegaly, lymphadenopathy, or cutaneous bleeding. The thyroid gland was not enlarged and the external genitalia were normal.

The blood picture at the first examination was normal. Haemoglobin 10.9 g. $/ 100 \mathrm{ml}$, haematocrit $32 \%$, and leucocytes $7,250 \mathrm{c} . \mathrm{mm}$., with normal differential count.

For 14 months the girl was observed at the out-patient clinic. As primordial dwarfism was thought to be the most likely diagnosis, no treatment was applied.

At the end of December 1962, at the age of 2 years and 3 months, the girl was admitted to hospital for further investigations. The physical examination on admission did not reveal any new pathological findings. Her weight was $6,450 \mathrm{~g}$., and her height $64 \mathrm{~cm}$. The initial blood count was again within normal limits. Sedimentation rate: $90 / 120$ (Westergren). Total proteins: $5 \cdot 7 \mathrm{~g}$./ $100 \mathrm{ml}$, albumin $2.7 \mathrm{~g} . / 100 \mathrm{ml}$., globulin $3.0 \mathrm{~g} . / 100 \mathrm{ml}$. Electrophoresis showed marked hypoalbuminaemia and $\alpha_{L}$-hyperglobulinaemia. Other liver function tests were normal. The blood levels of urea, electrolytes, calcium, and phosphorus were all within normal limits. The alkaline phosphatase level was below normal. Radiographs of the chest and skull were normal, whereas those of the wrist showed a severely retarded bone-age, of 6 months (Greulich and Pyle). On intravenous pyelography the left kidney could not be visualized. Proteinbound iodine in the serum was determined in order to rule out a thyroid-dependant dwarfism and high levels were found on several occasions, i.e. more than $16 \mu \mathrm{g} . / 100 \mathrm{ml}$. Further investigation in both the patient's mother and sister revealed the same high levels of PBI, but normal values were found in the father and maternal grandmother. The mother was euthyroid and her basal metabolic rate was normal.

A few days after admission, without any previous acute illness, petechiae appeared for the first time. From then and until death nine months later, the clinical course was dominated by haematological manifestations. There was no further practical possibility of determining her endocrine status, the origin of the dwarfism, nor of investigating the urinary tract. 
The haemogram showed anaemia (Hb $8 \cdot 2$ g. $/ 100 \mathrm{ml}$.), leucopenia $(3,700 / \mathrm{c} . \mathrm{mm}$.), and thrombocytopenia $(40,000 /$ c.mm.). In the peripheral blood smears anisocytosis, hypochromia, and macrocytosis were seen, and on several occasions normoblasts. Among the white blood cells myelocytes and metamyelocytes were evident. Differential count always showed a relative lymphocytosis. Red cells were between 2 and 3 million/c.mm. Bleeding time was $4 \cdot 5$ minutes, and the prothrombin consumption test showed a low value $(55 \%)$. No thrombo-agglutinins could be detected, and no lupus erythematosis cells. The direct Coombs test was negative as were the Kahn and Wassermann tests. On one occasion a high level of foetal haemoglobin $(5 \cdot 7 \%)$ was determined, but no other haemoglobinopathy could be found on haemoglobinelectrophoresis.

Bone marrow, aspirated on different occasions from the iliac crest, the tibia, and the vertebral spine, revealed extreme hypoplasia. Almost no younger elements were seen, but there was a relatively high number of lymphocytes and a few megaloblasts; no megakaryoblasts were detected.

The radioactive ${ }^{59} \mathrm{Fe}$ clearance test confirmed our diagnosis of aplastic anaemia and in addition showed signs of blood loss.

The blood picture during the last 9 months of the patient's life can be briefly summarized. The haemoglobin fell steadily, and repeated transfusions were required, 13 in all being given. Reticulocytes were below $1 \%$, except for two isolated occasions when counts of about $3 \%$ were recorded. The leucocytes also tended to fall gradually, from an initial level of 3,700 to a preterminal level of $1,200 / \mathrm{c} . \mathrm{mm}$. Thrombocytes varied between 10,000 and $50,000 / \mathrm{c} . \mathrm{mm}$.

During the first weeks of her haemorrhagic illness-due to thrombocytopenia- $45-20 \mathrm{mg}$. of prednisolone was given a day without benefit. The patient was therefore placed (three months after the first bleeding signs) on triamcinolone $8 \mathrm{mg}$. per day and methyltestosterone 10-20 mg. per day. During a 6-month period on this regimen no improvement was seen. The haemoglobin level continued to fall, there was no sustained reticulocytosis, and the bone-marrow remained apl'stic. The child developed severe side-effects of the combined corticosteroid and anabolic therapy: moon face, generalized osteoporosis, oedema of both legs, hirsutism, and acne. For one month, folic acid (15 mg. a day), vitamin C (100 mg. a day), and oral iron ( $0.6 \mathrm{~g}$. a day) were added.

The patient suffered several severe intercurrent febrile attacks caused by respiratory illnesses and by a urinary tract infection due to Esch. coli. In February-March 1963 there was a prolonged febrile period without any obvious cause, perhaps due to septicaemia. Blood cultures showed Esch. coli and Staph. albus. The patient received intensive antibiotic treatment.

Her general condition remained satisfactory until September 1963, when the bleeding tendency increased, and for the first time haematuria, melaena, and haematemesis appeared, and her condition deteriorated rapidly. Extreme apathy became evident and a tremor of both upper extremities, probably due to a central nervous system haemorrhage. Gradually dyspnoea, jaundice, uraemia, and signs of acute haemorrhagic enterocolitis appeared and the patient died in September 1963 at the age of 3 years, nine months after the first manifestations of the hypoplastic anaemia.

Necropsy. This revealed a well-nourished girl measuring $67 \mathrm{~cm}$. in length and weighing $6,200 \mathrm{~g}$. The skin showed a mild icteric tint and multiple petechiae and ecchymoses scattered over the body and extremities. Both eyes were smaller than normal.

On examination of the thoracic cavity multiple small haemorrhages were seen in the visceral pleurae. The lungs weighed 60 and $65 \mathrm{~g}$. and showed severe congestion and focal bronchopneumonia. The heart was normal.

The peritoneum, omentum, and mesentery were dotted with multiple haemorrhages. Similar pin-point haemorrhages were found in the mucosa of the entire gastrointestinal tract. The liver histologically showed Kupffer cells containing a moderate amount of haemosiderin. The spleen was hypoplastic ( $4 \mathrm{~g}$.) as compared to a normal $37 \mathrm{~g}$. for this age. There was a marked depletion of lymphatic tissue as well as severe haemosiderosis of the reticuloendothelial cells. A double fused kidney with double ureter was found on the right side, histologically showing acute pyelonephritis with a moderate amount of haemosiderin in the interstitial tissue.

Examination of the endocrine system showed that the right adrenal was absent; the left was small, $10 \times 10 \times 2$ $\mathrm{mm}$., with the cortex less than $1 \mathrm{~mm}$. in width. Microscopically, the normal organization of the cortex was well preserved, though there was a depletion of lipids. The thyroid isthmus was missing, each lobe measured $10 \times 5$ $\times 4 \mathrm{~mm}$., and showed follicles of varying diameter filled with colloid and lined by low cuboidal epithelium, without interstitial fibrosis. The ovaries were very small, $10 \times 3 \times 2 \mathrm{~mm}$. and contained only a few ova within a fibrotic stroma. A small pituitary gland, $2 \mathrm{~mm}$. in diameter, was situated in a small flat sella turcica and was covered by a thick layer of dura. Histologically no basophils could be identified with haematoxylin and eosin or PAS-orange G stains; eosinophils constituted about $40 \%$ and chromophobe cells about $60 \%$ of all cells of the anterior lobe.

The thymus weighed $8 \mathrm{~g}$.; it was yellow and of soft consistency: histologically there were small groups of lymphocytes with few Hassal-bodies scattered in fatty and fibrous tissue.

The brain weighed $535 \mathrm{~g}$. A subarachnoid haemorrhage was present above the right fronto-parietal lobe as well as a small cortical haemorrhage in the right parietal region. Cut sections of the brain revealed marked dilatation of all ventricles (Fig.), absence of the septum pellucidum, and extreme stenosis of the aqueduct of Sylvius at the mid-brain to a diameter of $0.5 \mathrm{~mm}$.

The bone-marrow was aplastic and was composed of fatty tissue and young connective tissue fibres. It contained a few small groups of non-identifiable haematopo:etic cells and large quantities of haemosiderin. 


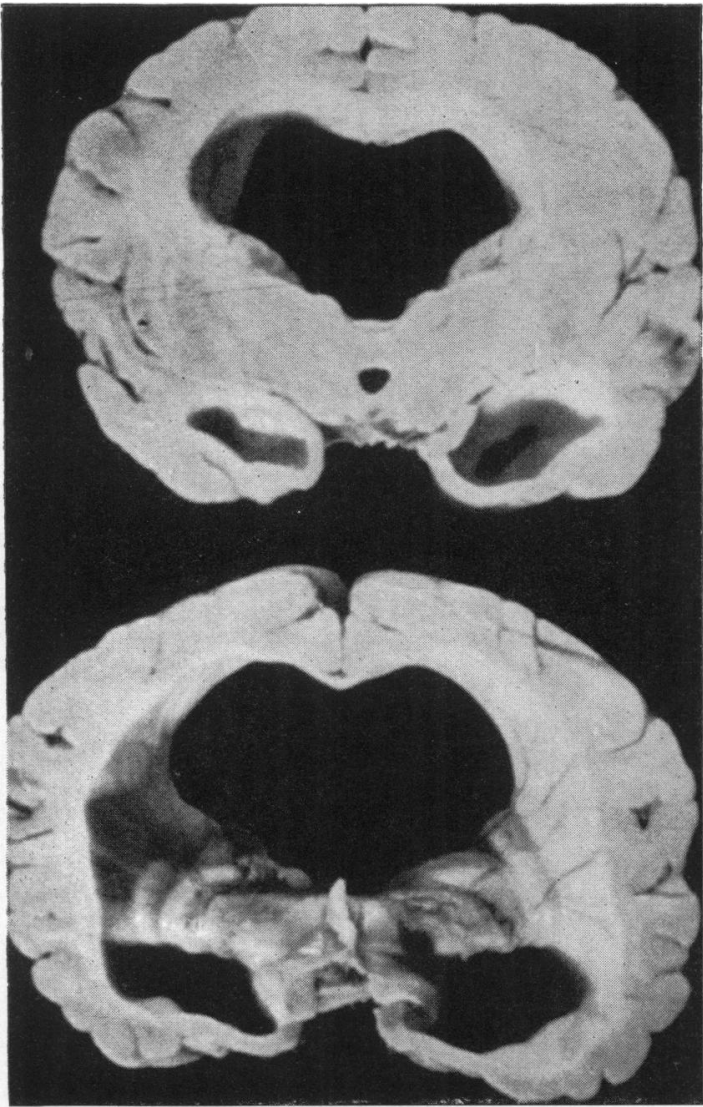

FIG.-Coronal sections of the brain, showing internal hydrocephalus and absence of septum pellucidum.

\section{Discussion}

In this case, the diagnosis of Fanconi's anaemia was based on the severe pancytopenia, dwarfism, and multiple congenital malformations found. According to some authors (Gasser, 1961; Kopyść and Lehnert, 1962) this diagnosis cannot be established without the presence of abnormal pigmentation of the skin and/or mucous membranes, caused by an aberration of melanin metabolism (McDonald and Goldschmidt, 1960; Wintrobe, 1961), a criterion that was not fulfilled in this patient. The disease, however, manifested itself earlier than usual (at the age of 2 years) and its duration was short. Therefore, it may be that the pigmentation would have ultimately appeared, had the child remained alive longer.

Although microcephaly is a very frequent malformation in this syndrome (McDonald and Goldschmidt, 1960), no other case of hydrocephalus, to our knowledge, has been described. Kunz (1952) mentioned that the brother of his case of Fanconi's anaemia died at the age of 17 months from obstructive hydrocephalus without any haematological symptoms during life. In the present case the hydrocephalus was not recognized during life because it was symptomless, and the patient's head was of fairly normal size for her age, being enlarged only in relation to the size of her body.

The necropsy revealed severe hypoplasia of the spleen and of almost all endocrine glands; the pituitary, the thyroid, the left adrenal, the ovaries; and, in addition, the right adrenal was absent. These endocrinological findings may be regarded as congenital malformations, for they are found in Fanconi's anaemia, but they might have been the result of prolonged hormonal treatment. The presence of a small pituitary situated in a corresponding small sella turcica points towards a true congenital malformation of the pituitary and to a primary congenital hypopituitarism. Thus the dwarfism and the absence of pigmentation can be easily understood. Though in many cases of Fanconi's anaemia retarded growth is present (Kunz, 1952; Cowdell, Phizackerley, and Pyke, 1955), in only 2 reported cases has the pituitary been examined at necropsy, and in both these it was found to be hypoplastic as in our patient. Hypoplasia of the thyroid was found at necropsy in both cases of Cowdell et al. (1955), and hypoplasia of the spleen was described by Wintrobe (1961).

On several occasions high PBI-serum levels were found in our patient, and also in both her mother and her younger sister. All were euthyroid, without goitre. (The thyroid status of these relatives is at present being assessed.) Most probably we are dealing with either a hereditary enzymatic defect in hormone production, or a familial increase in thyroxine-binding-proteins (Beierwaltes and Robbins, 1959), both of which occur in rare instances. It remains therefore to be decided whether there is any pathogenetic connexion between these endocrine anomalies and the hypoplastic anaemia. Alternatively, the family might be affected by two independent hereditary traits.

The pancytopenia was resistant to a combined therapy of corticosteroids and testosterone in the advised dosages (triamcinolone $4 \mathrm{mg}$./day, methyltestosterone $1-2 \mathrm{mg} . / \mathrm{kg}$. day) during a period of 6 months. Because of technical reasons testosterone could not be given in the form of buccal linguets, and was therefore given orally in a higher dose $(3 \mathrm{mg} . / \mathrm{kg}$. day) in order to cope with the inactivation of the drug in the liver when given orally.

The lack of erythropoietic response is perhaps not surprising in the light of the extreme bone 
marrow aplasia in this patient. The side-effects of the therapy were related in the first place to the action of the corticosteroids (moon face, oedema of the legs). Testosterone therapy led to acne and hirsutism. The jaundice in the final stage of the disease had an obstructive character and was perhaps due to prolonged testosterone administration. Of interest was the generalized osteoporosis in spite of the testosterone therapy, while the boneage failed to advance during this therapy.

\section{Summary}

A case is described of Fanconi's anaemia in a girl who suffered from dwarfism due to congenital hypoplasia of the pituitary and from other congenital malformations. The pancytopenia manifested itself at the age of 2 years and was resistant to a combined corticosteroid-testosterone treatment. Unusual findings in this case were congenital hydrocephalus, hypoplastic spleen, and hypoplasia of thyroid together with persistently high PBI serum levels but without apparent changes in thyroid function.

\section{REFERENCES}

Beierwaltes, W. H. and Robbins, J. (1959). Familial increase in the thyroxine-binding sites in serum alpha globulin. J. clin. Invest., 38, 1683.

Cowdell, R. H., Phizackerley, P. J. R., and Pyke, D. A. (1955) Constitutional anemia (Fanconi's syndrome) and leukemia in two brothers. Blood, 10, 788.

Fanconi, G. (1927). Familiäre infantile perniziosaartige Anämie (perniziöses Blutbild und Konstitution). Jb. Kinderheilk., 117, 257.

Gasser, C. (1961). Panmyelopathien im Kindesalter. Beitrag zur Fanconi-Anämie. Helv. paediat. Acta, 16, 752.

Kopyśc, Z., and Lehnert, A. (1962). Pancytopenia 3 licznymi wadami rozwojowymi typu Fanconiego. (Pancytopenia with numerous developmental defects of Fanconi type.) Pediat. pol., 37, 295.

Kunz, H. W. (1952). Hypoplastic anemia with multiple congenital defects (Fanconi syndrome). Pediatrics, 10, 286.

McDonald, R. (1962). Drug-induced remission in hypoplastic anaemia (Fanconi type.) S. Afr. med. J., 36, 310.

- - and Goldschmidt, B. (1960). Pancytopenia with congenital defects (Fanconi's anaemia). Arch. Dis. Childh., 35, 367.

Nilsson, L. R. (1960). Chronic pancytopenia with multiple congenital abnormalities (Fanconi's anaemia). Acta paediat. (Uppsala), 49, 518.

Shahidi, N. T., and Diamond, L. K. (1959). Testosterone-induced remission in aplastic anemia. Amer. J. Dis. Child., 98, 293.

- - (1961). Testosterone-induced remission in aplastic anemia of both acquired and congenital types. New Engl. J. Med., 264, 953.

Wintrobe, M. M. (1961). Clinical Hematology, 5th ed., p. 561. Kimpton, London. 